\title{
Prevalence of Overweight and Obesity in Adolescents: A Systematic Review
}

\author{
Maria del Mar Bibiloni, ${ }^{1,2}$ Antoni Pons, ${ }^{1,2}$ and Josep A. Tur ${ }^{1,2}$ \\ ${ }^{1}$ Research Group on Community Nutrition and Oxidative Stress, University of Balearic Islands, 07122 Palma de Mallorca, Spain \\ ${ }^{2}$ CIBERobn (Fisiopatología de la Obesidad y la Nutrición CB12/03/30038), Instituto de Salud Carlos III, \\ 15706 Santiago de Compostela, Spain
}

Correspondence should be addressed to Josep A. Tur; pep.tur@uib.es

Received 12 May 2013; Accepted 10 June 2013

Academic Editors: G. González-Cuevas, D. Micic, E. K. Naderali, and R. Tungtrongchitr

Copyright (C) 2013 Maria del Mar Bibiloni et al. This is an open access article distributed under the Creative Commons Attribution License, which permits unrestricted use, distribution, and reproduction in any medium, provided the original work is properly cited.

\begin{abstract}
Objective. To review the extant literature on the prevalence of overweight and obesity in adolescents (10-19 years old) of both sexes. Design. The search was carried out using Medline and Scopus considering articles published from the establishment of the databanks until June 7, 2012. Data on the prevalence of children being overweight and obese from the International Obesity Task Force (IOTF) website was also reviewed. Only original articles and one National Health Report were considered. Forty studies met the inclusion criteria. Results. Twenty-five of these studies were nationally representative, and ten countries were represented only by regional data. Conclusions. The prevalence of overweight and obesity among adolescents worldwide is high, and obesity is higher among boys. The IOTF criterion is the most frequently used method to classify adolescents as overweighed or obese in public health research.
\end{abstract}

\section{Introduction}

The prevalence of overweight and obesity among children and adolescents has widely increased worldwide $[1,2]$, making it one of the most common chronic disorders in this age group and in adulthood.

The use of body mass index (BMI) for age to define being overweight and obese in children and adolescents is well established for both clinical and public health applications, because of their feasibility under clinical settings and in epidemiological studies $[3,4]$. In children and adolescents, the natural increases in BMI that occur with age necessitate the use of age-sex-specific thresholds. The most widely used growth charts are the Centers for Disease Control and Prevention (CDC-2000) [5], the International Task Force (IOTF) [6], and the 2007 growth references for 5 to 19 year olds produced by the World Health Organization (WHO-2007) [7].

The CDC-2000 growth charts were developed to evaluate the nutritional status of US children and were originated from five cross-sectional representative surveys carried out in the
US between 1963 and 1994. These growth charts are routinely applied to identify children and adolescents with a BMI greater than the 85th or 95th percentiles following the advice of the US Expert Committee on Childhood Obesity [8]. However, the appropriateness of an American dataset for defining overweight in young people from other countries is questionable [9].

The IOTF reference also uses age-sex-specific BMI percentiles, and overweight and obesity definition corresponds to an adult BMI of 25 and $30 \mathrm{~kg} / \mathrm{m}^{2}$, respectively, and reflects values in children tracking to overweight and obesity in adults [6]. This reference is based on six large international crosssectional representative datasets, identifying the BMI values that extrapolate to childhood.

The WHO-2007 growth references were created to replace the National Center for Health Statistics (NCHS) references $[10,11]$. This reference was constructed using data from the 1977 NCHS/WHO growth reference (1 to 24 years old) merged with data from the 2006 WHO Child Growth Standards for preschool children (under 5 years of age) using state-of-the-art statistical methods [7]. 


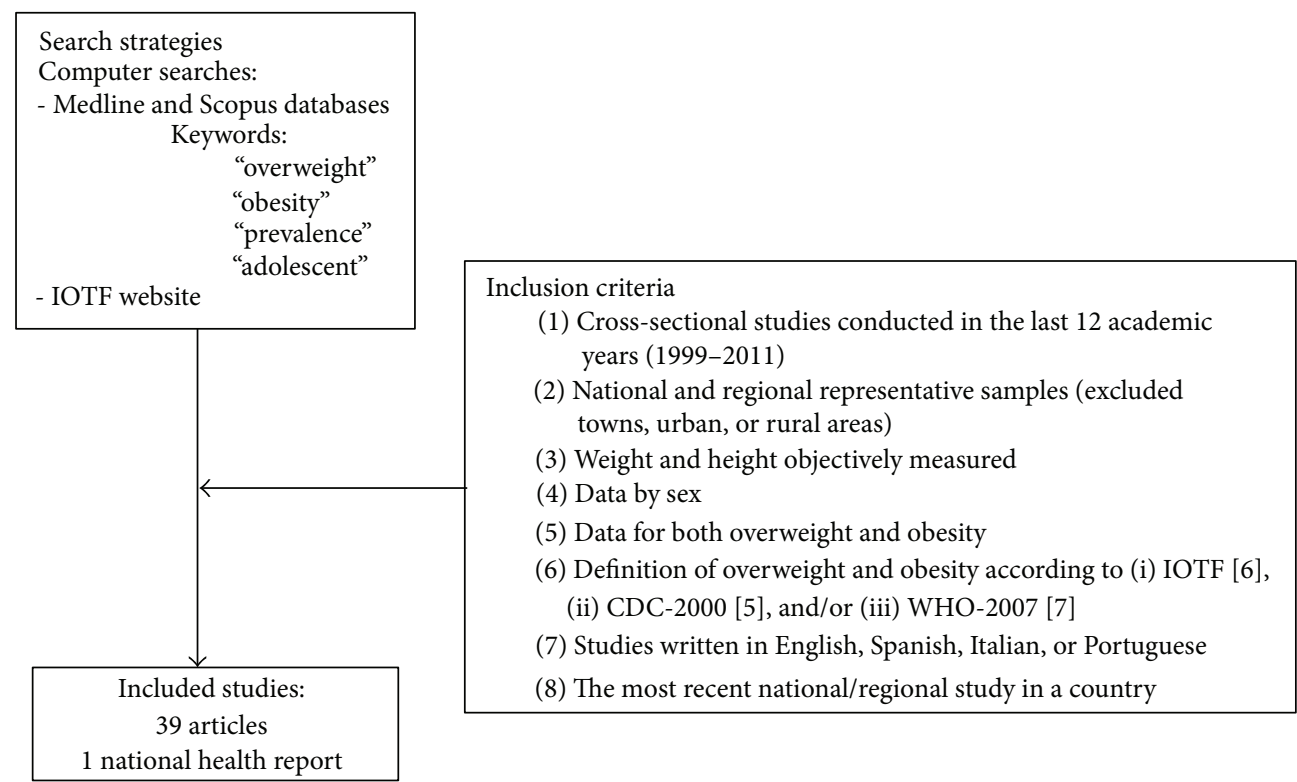

Figure 1: Flow diagram of study selection.

Although valuable information has been appearing in the literature or online, such as works from the Health Behaviour of School-aged Children study which is mainly related to social determinants of health and well-being among young people [12], no systematic review has been conducted to understand the worldwide magnitude of the overweight and obesity problem among the adolescent population. Thus, the objective of this study was to systematically review the literature regarding the prevalence of overweight and obesity in adolescents (10-19 years old) of both sexes published in the past 12 academic years (1999-2011).

\section{Methods}

A systematic literature search was performed which ended on June 7, 2012 (see Figure 1). The literature search was conducted in Medline and Scopus using the following $\mathrm{MeSH}$ terms: "overweight"; "obesity"; "prevalence"; "adolescent". In total, 2537 articles were selected. We also reviewed the data on the prevalence of childhood overweight and obesity on the International Obesity Task Force Website at http://www .iaso.org/iotf/. To find the articles included in this review, the following inclusion criteria were used: (1) cross-sectional studies conducted in the last 12 years (1999-2011) — when the original study did not report the survey year, it was not included; (2) national and regional representative samples, but articles published on the prevalence of overweight in towns, urban, or rural areas in a country were excluded; (3) weight and height objectively measured; (4) results presented by sex; (5) and for both overweight and obesity prevalence; (6) the definition of overweight and obesity using the (i) CDC-2000 [5], (ii) IOTF [6], and (iii) WHO-2007 [7] growth references; and (7) studies written in English, Spanish, Italian, or Portuguese. Moreover, if there were more than one national or regional study in the same country, the most recent one was included in the prevalence tables (except for USA [13] and Canada [14], countries in which the most recent data was not included in the tables due to differences in the representativeness of the samples [13] and the impossibility to calculate a single prevalence of overweight and obesity for adolescents' boys and girls [14]; however, no differences in prevalence were observed between studies as it has been indicated in the discussion). The final number of articles included in this review was 39 articles related to overweight and obesity and also a study on the latest statistics on the prevalence of overweight and obesity in South Africa [15].

Potentially relevant papers were selected by (1) screening the titles; (2) screening the abstracts, and (3) if abstracts were not available or did not provide sufficient data, the entire article was retrieved and screened to determine whether it met the inclusion criteria. Full-text articles were assessed by 2 authors (M. M. Bibiloni and J. A. Tur). Any matter of doubt was discussed by at least two of the reviewers (M. M. Bibiloni, A. Pons, and J. A. Tur).

\section{Results}

3.1. Literature Search. A total of thirty-nine articles and a National Health Report were eligible according to the inclusion criteria established for this review. Table 1 presents a description of the forty studies selected for this review including the continent and the country where it was performed (and region for not national studies), year of publishing, total number of participants in the study, number of adolescents, age range, proportion of girls, and number and definition for overweight and obesity classification used. All the articles were published after the year of 2002. Nationally representative data were obtained in twenty-five countries (including Northern Ireland) [15-39], and ten countries were represented only by regional data $[40,42,44,45,47,50-54]$. 


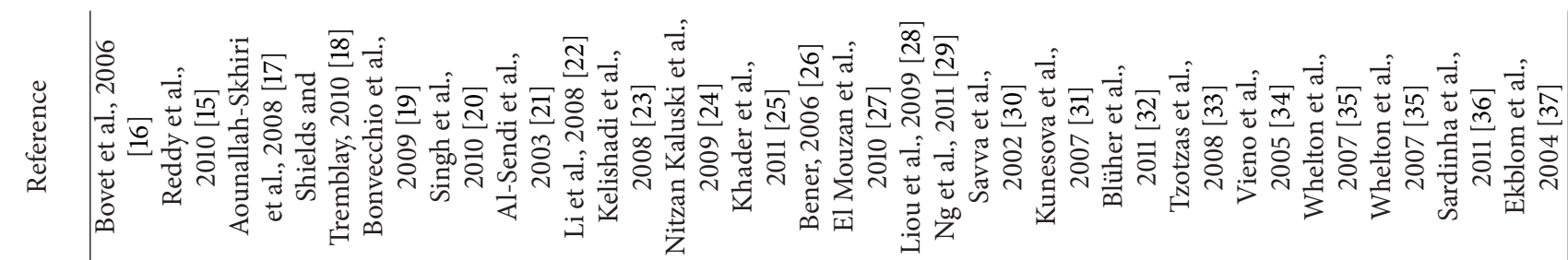

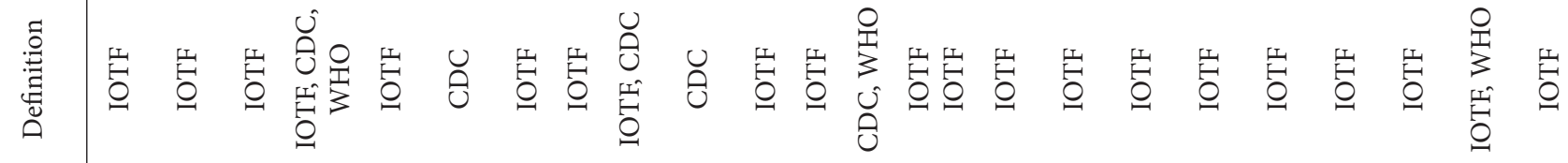

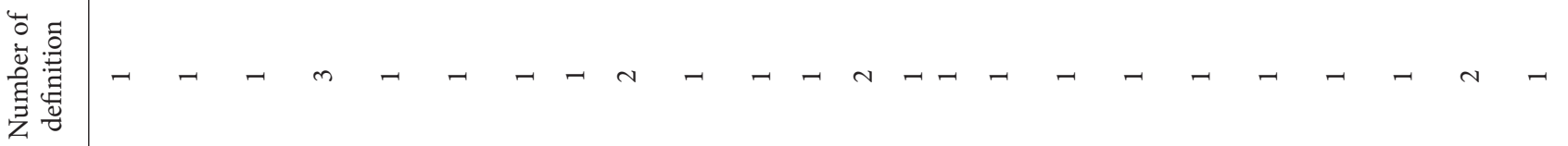

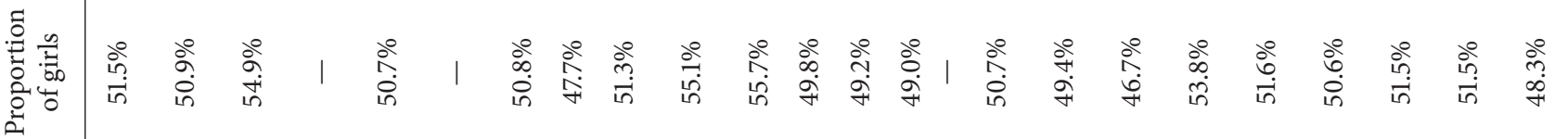

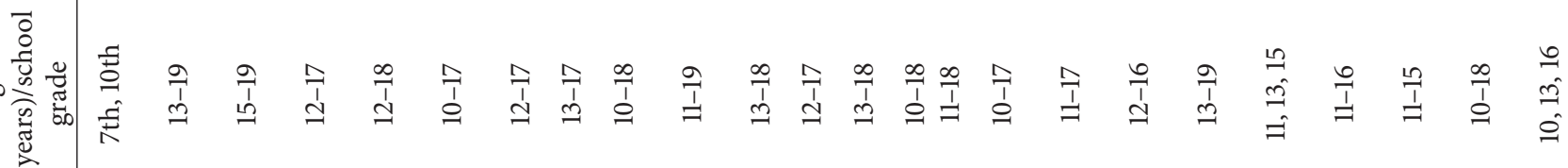

पे

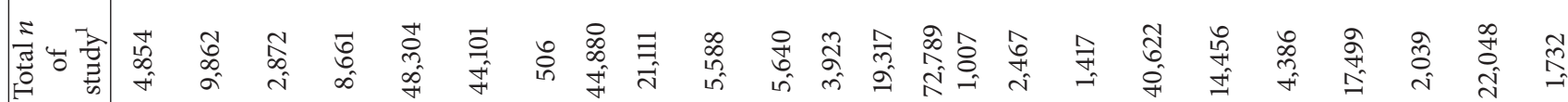
गे

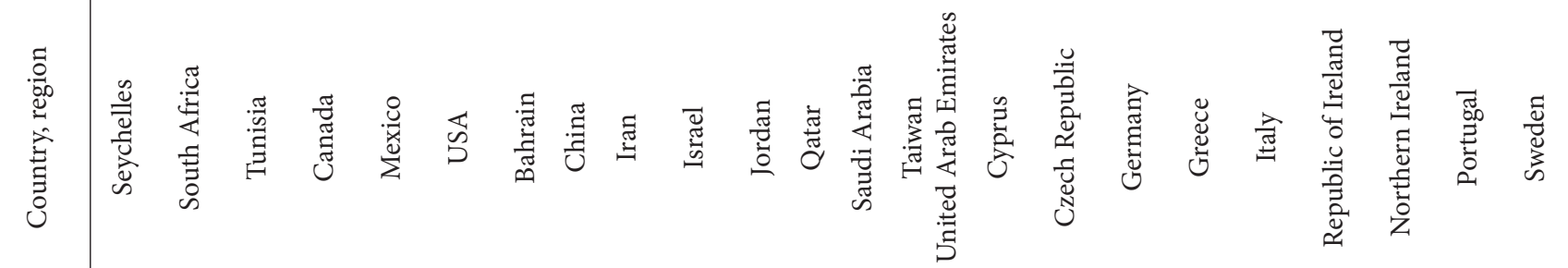

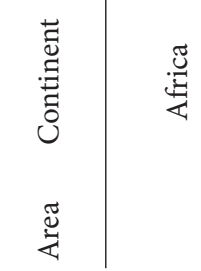
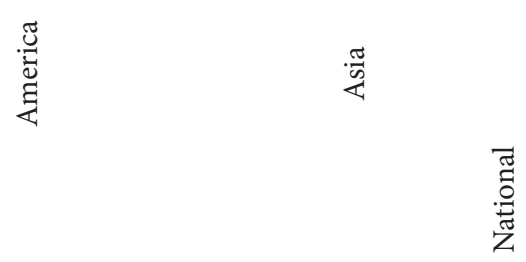

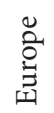




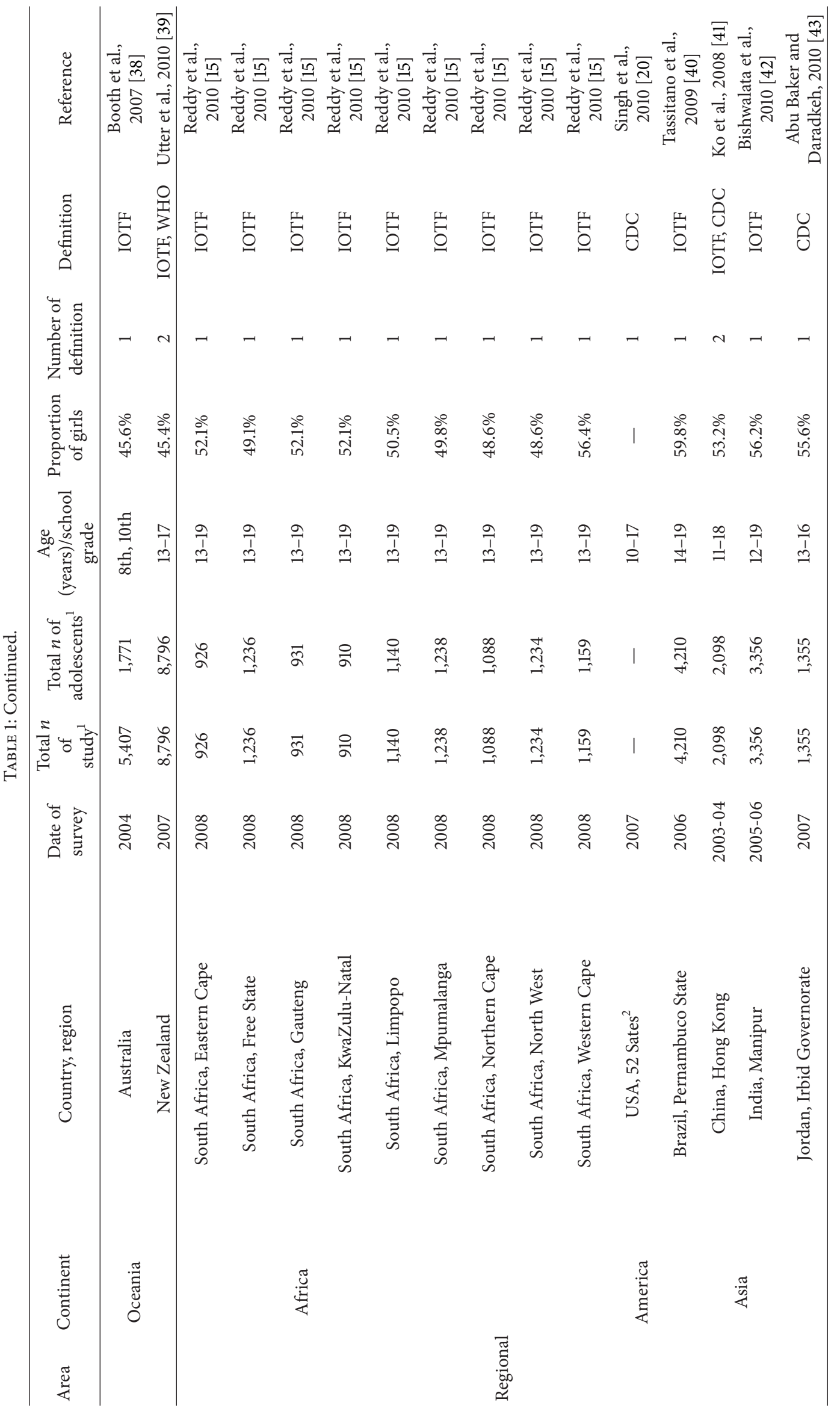




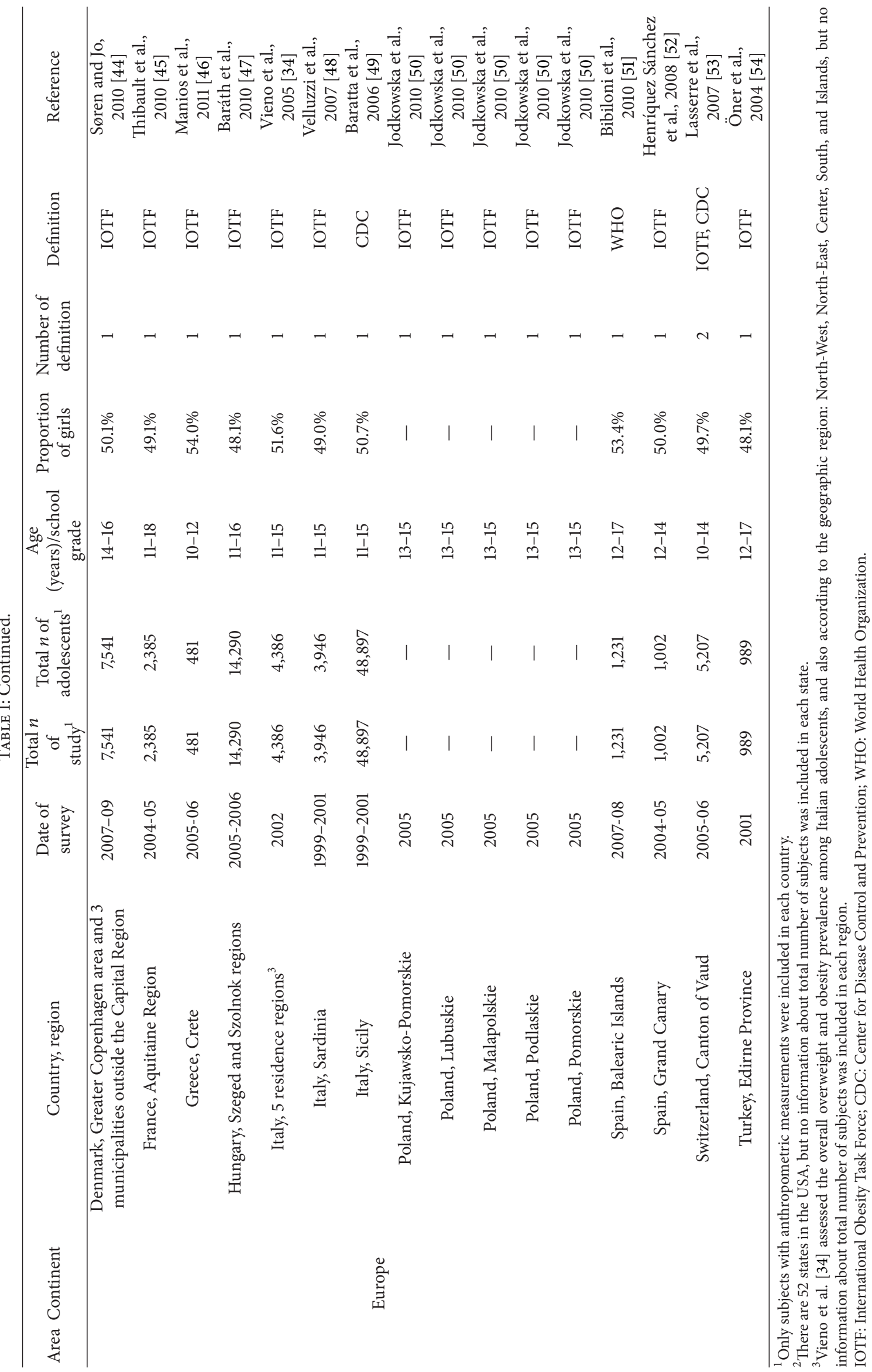


3.2. Prevalence and Criteria for Classification. Table 2 shows overweight and obesity prevalence from the twenty-five national studies (one of them including data from Northern Ireland) that were included in this review according to the continent and the country where it was performed, year of survey, study population, age range, criteria used for classifying overweight and obesity used, and along with total data by sex. There were thirty-two different prevalence levels described in the included articles, because five countries presented data using at least two different criteria for overweight and obesity classification $[18,23,27,36,39]$. The IOTF cut-off was used to classify overweight and obesity in twenty-three of the twenty-five national studies considered in the present review.

There was a broad range of overweight and obesity prevalence noted. In general, the prevalence of overweight plus obesity was higher in America [18-20], Oceania [38, 39] and Europe [30-37] and lower in Africa [15-17] and certain parts of Asia [21-29] (in China [22] and Iran [23] the total prevalence was less than $10 \%$ by the IOTF cut-offs). Overall, about $30 \%$ of American adolescents and 22\%-25\% of European adolescents (excepting the Czech Republic and Italian adolescents' which showed a prevalence of $13.7 \%$ and $17.9 \%$, resp.) were overweight or obese. Among Oceanian adolescents the prevalence ranged from 23.2\% in Australia in 2004 to $34.2 \%$ in New Zealand in 2007. In Africa, the overall prevalence of overweight and obesity was lower than $20 \%$. Among Asian adolescents there was a broad range of overweight plus obesity. Using IOTF cut-off, the prevalence of being overweight or obese for Asian boys and girls ranged from 5.2\% in China in 2002 to 36.4\% in Bahrain in 2000.

Table 3 shows regional data prevalence of overweight and obesity from fifteen countries. Specific prevalence from all the geographic regions was included in this review from three countries: South Africa (nine provinces) [15], USA (fifty two states) [20], and Italy (five regions) [34]. In Europe, data from islands of Greece (Crete) [46] and Italy (Sicily and Sardinia) $[48,49]$ and Spain (Balearic Islands' archipelago [51]; and the Grand Canary Island [52]) were also included. On the other hand, regional but not national data was found for eleven countries (Italy [34], Brazil [40], India [42], Jordan [43], Denmark [44], France [45], Hungary [47], Poland [48], Spain [51, 52], Switzerland [53], and Turkey [54]). The IOTF cut-off was used to classify overweight and obesity in fourteen of the eighteen selected studies that included regional data. In one study [51], data was presented using only the WHO-2007 growth charts and in two studies using only the CDC-2000 growth reference [20,43].

In South Africa and USA, substantial geographic variations in adolescent overweight and obesity existed. In 2008, overweight and obesity prevalence varied in South Africa from $13.5 \%$ in Limpopo to $25.5 \%$ in KwaZulu-Natal. In 2007 , overweight and obesity varied in USA from $23.1 \%$ in Utah and Minnesota to $44.5 \%$ in Mississippi. In 2002, the prevalence of overweight and obesity in Southern Italy and Italian islands was higher among boys. In Southern Italy, the overweight prevalence among girls also was higher than in the other geographic regions.
Comparison between the islands from Greece (Crete), Italy (Sicily and Sardinia), and Spain (Balearic Islands and Grand Canary Island) which were included in this review showed that Crete had the highest prevalence of overweight and obesity-despite data were presented using different definition. In Spain, using the IOTF cut-off (data not shown for Balearic Islands but given by authors), the prevalence of overweight plus obesity was higher in the Grand Canary Island (29.1\%) than in the Balearic Islands (24.7\%).

3.3. Gender Differences. According to national data, the prevalence of overweight among boys was $\geq 10 \%$ higher than girls in nine countries (Canada [18], Qatar [26], Taiwan [28], Cyprus [30], Czech Republic [31], Germany [32], Greece [33], Italy [34], Australia [38], Denmark [44], and Hungary [47]) and among girls $\geq 10 \%$ higher than boys in seven of the twenty-five countries (South Africa [15], Seychelles [16], Tunisia [17], Mexico [19], Bahrain [21], Saudi Arabia [27], and Sweden [37]). The obesity prevalence was $\geq 10 \%$ higher among boys in seventeen countries (Canada [18], USA [20], China [22], Iran [23], Israel [24], Qatar [26], Saudi Arabia [27], Taiwan [28], Cyprus [30], Czech Republic [31], Germany [32], Greece [33], Italy [34], Portugal [36], Sweden [37], Australia [38], New Zealand [39], Denmark [44], and Hungary [47]) and $\geq 10 \%$ higher among girls in four of the twenty-five countries (South Africa [14], Seychelles [16], Tunisia [17], and Bahrain [21]).

\section{Discussion}

The aim of this study was to review systematically the literature on overweight and obesity prevalence among adolescents worldwide. Thirty-nine articles and one National Health Report that met the inclusion criteria were considered. The overweight and obesity prevalence in the included studies ranged widely. In sixteen of the twenty-three countries with national representative data using the IOTF cut-off, overweight and obesity prevalence higher than $20 \%$ were found, five countries showed prevalence above $30 \%$, and just in two countries prevalence was lower than $10 \%$.

Regarding national data, when prevalence was analysed according to sex, it was observed that boys showed a higher prevalence of overweight in almost half of the countries and a higher prevalence of obesity in almost all countries. These results are consistent with previous studies that pointed out a high prevalence of abdominal obesity among boys [55]. Differences of prevalence of overweight and obesity between genders have been related to geopolitical and cultural conditions [55].

Eight articles compared data between 1980s and/or 1990s with 2000s $[16,19,20,22,28,32,37,50]$ and pointed out an increased prevalence of overweight and obesity in both sexes over this period. However, among Australian adolescents [38] the overweight and obesity prevalence increased significantly among boys but not among girls over the period 1997-2004. In the Australian National Children's Nutrition and Physical Activity Survey 2007 (NCNPAS07) [14], 25\% of boys and 30\% of girls aged 9 - to 13 -year-olds and $25 \%$ of boys and $23 \%$ of girls aged 14- to 16-year-olds were overweight or obese using 


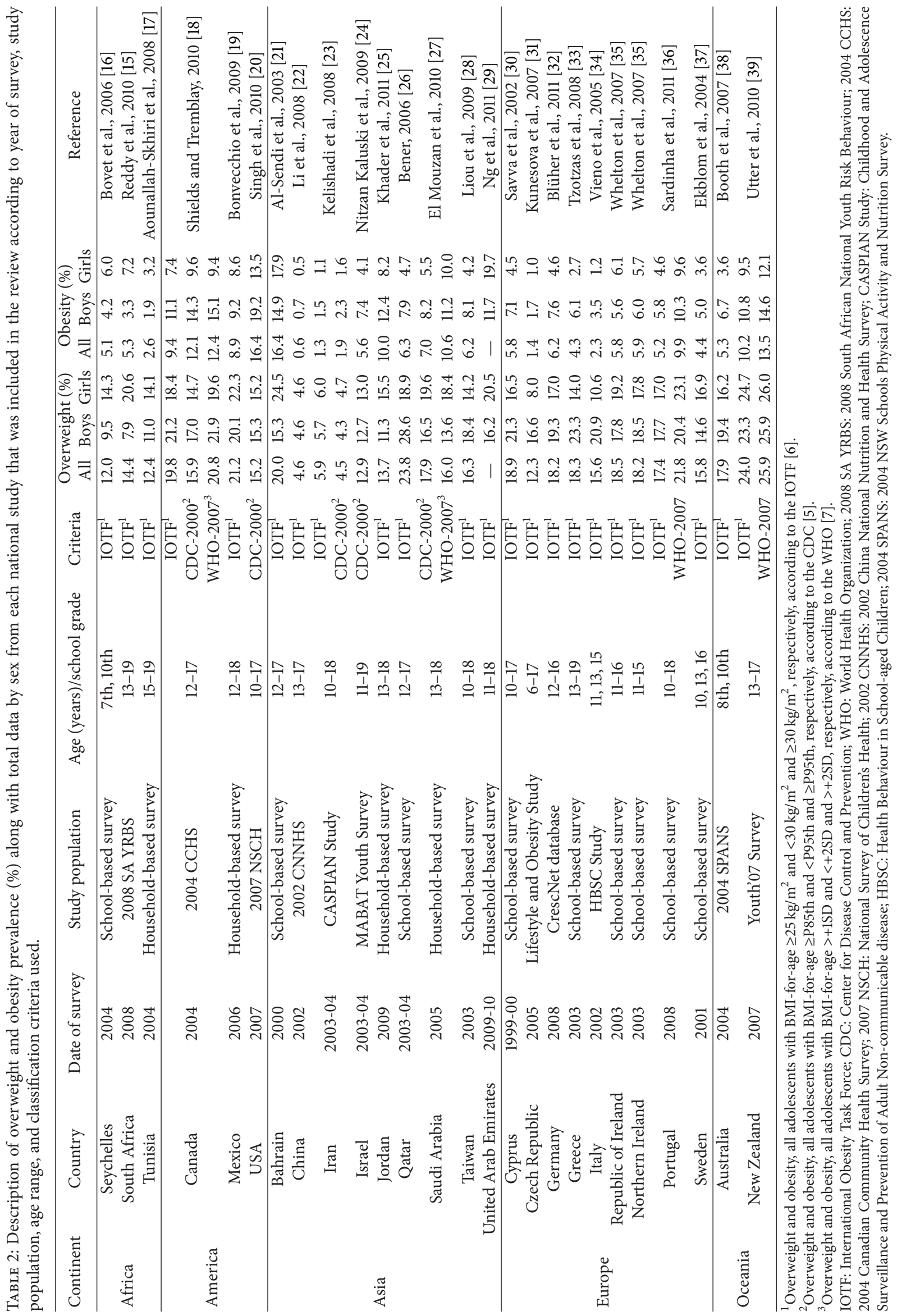




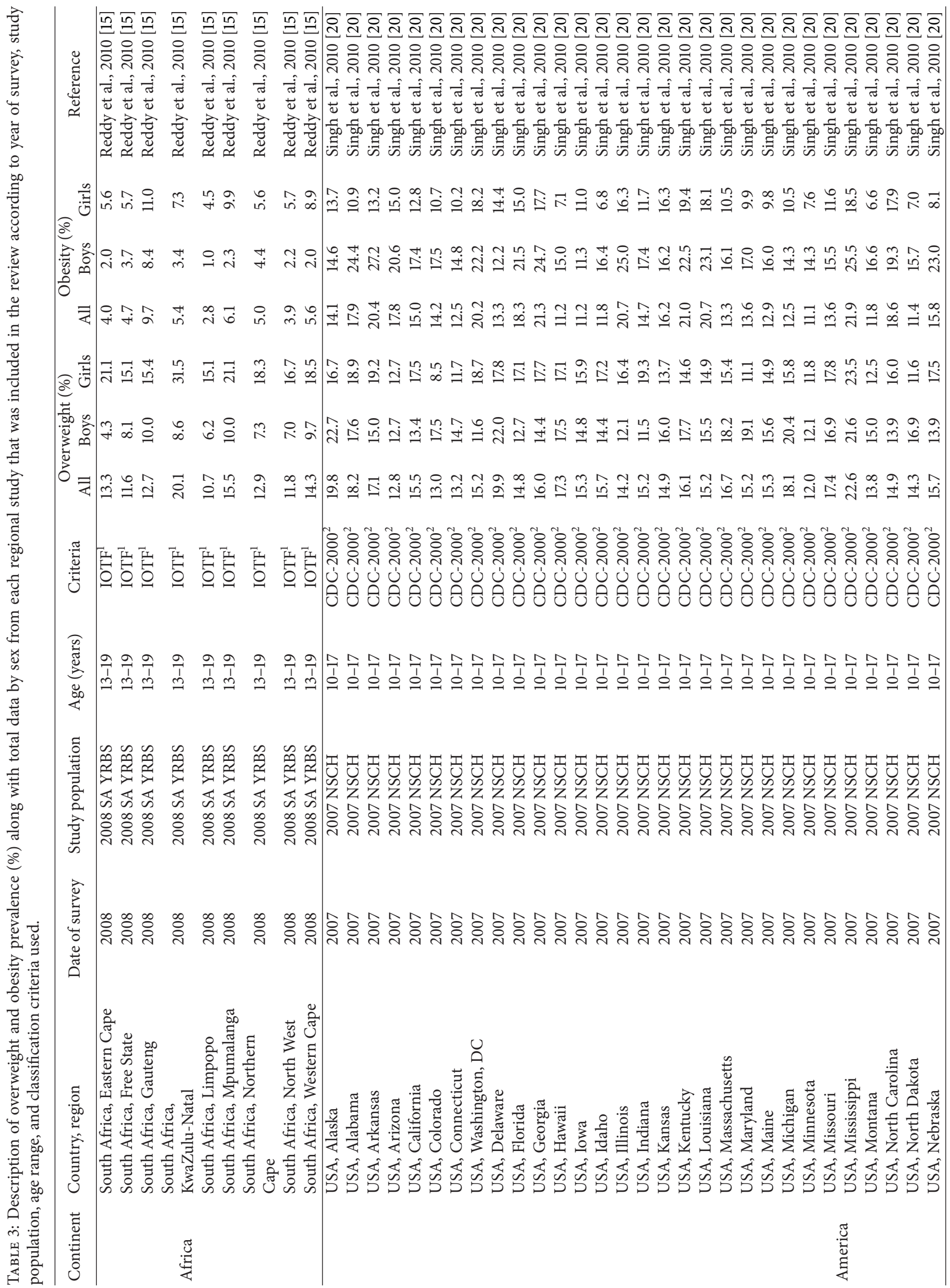




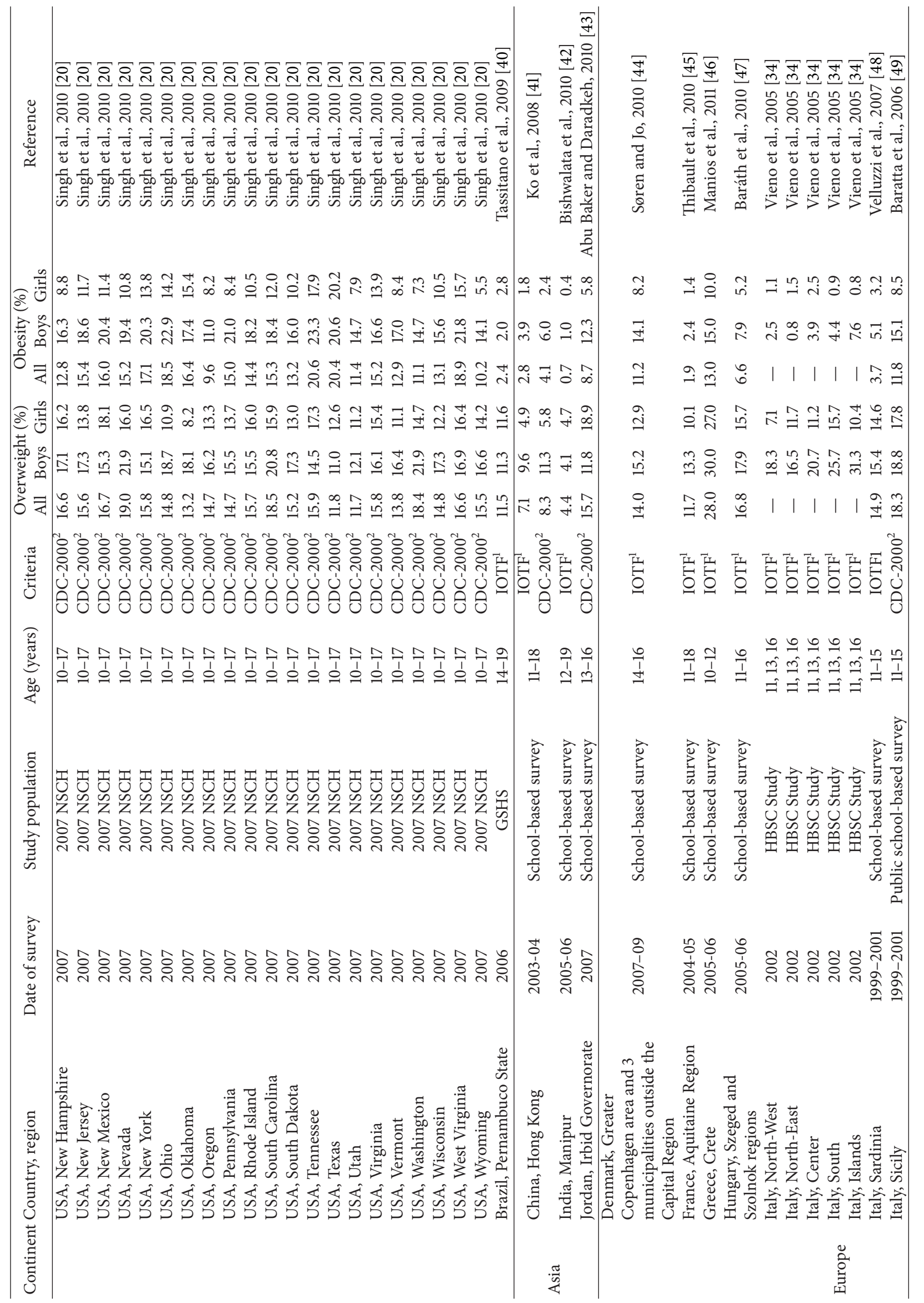




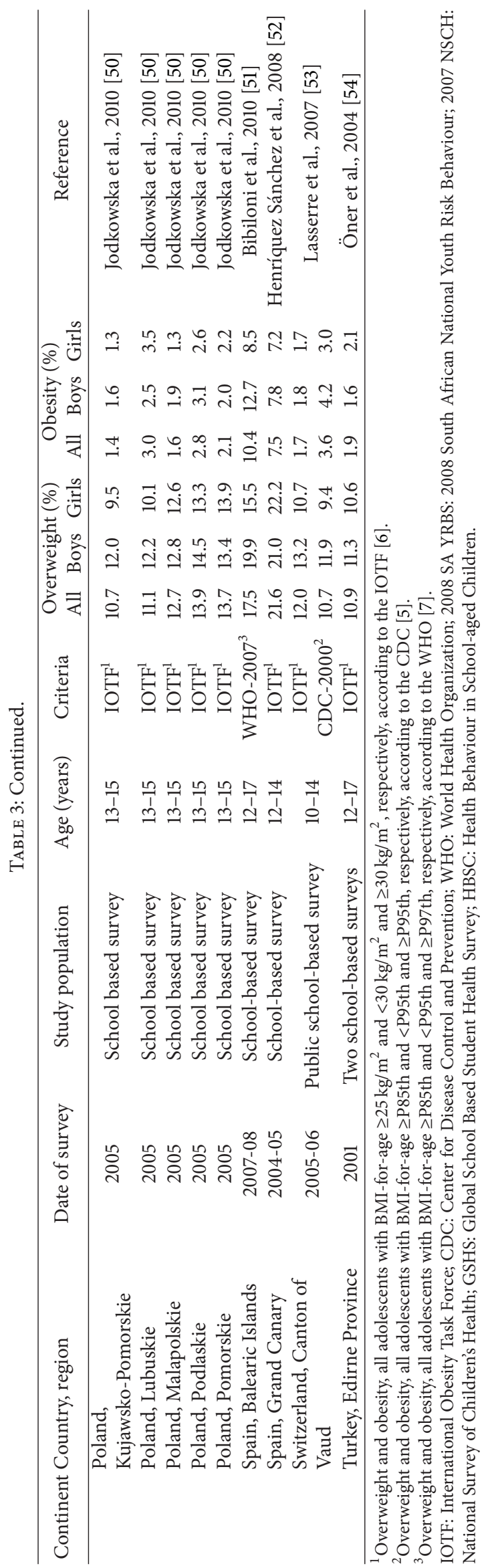


the IOTF criteria. A comparison of the 1985, 1995, and 2007 Australian national surveys of 7- to 15 -year-olds indicated that Australian children are changing body shape to a more central fat distribution [14]. In USA, overweight and obesity prevalence among adolescents increased 4\% in 2003 and 10\% in 2007. Overweight and obesity prevalence increased by $3 \%$ and $18 \%$ among USA girls over this period. However, a crosssectional analyses of a representative sample $(n=4111)$ of the USA child and adolescent population (birth through 19 years of age) with data from the National Health and Nutrition Examination Survey 2009-10 (NHANES) indicated a prevalence of overweight and obesity among adolescents aged 12 through 19 years of $15.2 \%$ and $18.4 \%$, respectively. Analyses of trends in obesity prevalence for the last two NHANES surveys (2007-08 and 2009-10) indicated that the prevalence of obesity in children and adolescents has not changed in 2009-10 compared with 2007-08 [13]. On the other hand, since 2004 the overweight and obesity trends were stabilized or decreased among German adolescents [32].

In USA, substantial geographic disparities in adolescent overweight and obesity were found, with an apparent shift toward higher prevalence in 2007 for several states [20]. Generally, overweight and obesity prevalence was also higher in southern USA in 2007. Lobstein et al. [56] reported that children in Northern Europe countries generally tended to have lower overweight and obesity prevalence (10-20\%) than in Southern Europe (20-35\%). Also within the same country, the prevalence and trends of overweight and obesity may not be homogeneous according to different geographic regions [57]. In Italy, a north-south gradient in overweight and obesity prevalence among boys but also in overweight prevalence among girls was also reported [34]. A higher prevalence of overweight and obesity has been reported in Southern Spain in both children [58] and adults [59].

It is important to note that the choice of a reference and a cut-off point will determine the absolute prevalence of overweight and obesity and its trends, and hence different information will be obtained from the papers [60]. The IOTF classification for adolescent overweight and obesity [6] is the most frequently used. Cole et al. [6] argued that the reference they published, supported by the IOTF, is less arbitrary and more international than others and recommended its use in international comparisons. Lately, Monasta et al. [61] suggested that the IOTF reference and cut-offs could be preferable to identify overweight and obesity both at individual and population levels because they are at least based on a crude association with ill and health later in life, namely, the definition of overweight and obesity at age 18 years. However, the IOTF cut-offs have been not recommended for clinical use when assessing an individual child's growth $[9,62-64]$. Furthermore, recent findings suggested that a universal BMI classification system for childhood and adolescent overweight and obesity may not correspond to a comparable level of body fatness in all populations [9]. The prevalence estimates may not accurately characterize the population groups most at risk of health disadvantages because the correlation of BMI with adiposity is highly variable and dependent on ethnic group $[9,60,65,66]$.

\section{Limitations of the Study}

The comparisons of overweight and obesity prevalence need interpretation with caution due to the difference in survey sampling methods, sample sizes, age range of subjects, quality of data in terms of height and weight measurement, and whether national programmes or strategies to tackle overweight and obesity are in place [57]. Even within the same country, the prevalence and trends of overweight and obesity may not be homogenous in view of different ethnicities, geographic regions, and socioeconomic status [57]. Only articles in English, Spanish, Italian, and Portuguese were included in this review.

\section{Conclusions}

The results of this review allow the following conclusions: (1) overweight and obesity prevalence is high; (2) obesity is higher among boys, although it is not clear which sex has a higher proportion of adolescents with overweight; (3) despite that there is no consensus about criteria to be used to classify adolescents as overweighed or obese, the most frequently used was the IOTF reference [6]. However, the international reference charts for monitoring the secular trends in childhood obesity need to be continually refined and evaluated [56]. The results of this study would contribute to guiding health planners and administrators to develop proper tools for adolescent obesity management.

\section{Conflict of Interests}

The authors state that there is no conflict of interests.

\section{Authors' Contribution}

Maria del Mar Bibiloni and Josep A. Tur contributed to the design of the strategy for the literature search and double screened and selected the retrieved documents. Antoni Pons provided previous literature searches and analysis. Maria del Mar Bibiloni and Josep A. Tur prepared the main outline of the paper and all authors contributed to the preparation of the paper.

\section{Acknowledgments}

The authors would like to thank the Spanish Ministry of Health and Consumption Affairs (Programme of Promotion of Biomedical Research and Health Sciences, Projects 05/1276 and 08/1259, and Red Predimed-RETIC RD06/0045/1004 and CIBERobn CB12/03/30038), Grant of support to research groups no. 35/2011 (Balearic Islands Government and EU FEDER funds), Spanish Ministry of Education and Science (FPU Programme, PhD fellowship to M.M.B.). The Research Group on Community Nutrition and Oxidative Stress, University of Balearic Islands belongs to the Centre Català de la Nutrició (IEC).

\section{References}

[1] C. B. Ebbeling, D. B. Pawlak, and D. S. Ludwig, "Childhood obesity: public-health crisis, common sense cure," The Lancet, vol. 360, no. 9331, pp. 473-482, 2002. 
[2] I. Lissau, M. D. Overpeck, W. J. Ruan, P. Due, B. E. Holstein, and M. L. Hediger, "Body mass index and overweight in adolescents in 13 European Countries, Israel, and the United States," Archives of Pediatrics and Adolescent Medicine, vol. 158, no. 1, pp. 27-33, 2004.

[3] A. Must and S. E. Anderson, "Body mass index in children and adolescents: considerations for population-based applications," International Journal of Obesity, vol. 30, no. 4, pp. 590-594, 2006.

[4] J. J. Reilly, "Diagnostic accuracy of the BMI for age in paediatrics," International Journal of Obesity, vol. 30, no. 4, pp. 595$597,2006$.

[5] R. J. Kuczmarski, C. L. Ogden, S. S. Guo et al., "2000 CDC Growth Charts for the United States: methods and development," Vital and Health Statistics, no. 246, pp. 1-190, 2002.

[6] T. J. Cole, M. C. Bellizzi, K. M. Flegal, and W. H. Dietz, "Establishing a standard definition for child overweight and obesity worldwide: international survey," British Medical Journal, vol. 320, no. 7244, pp. 1240-1243, 2000.

[7] M. De Onis, A. W. Onyango, E. Borghi, A. Siyam, C. Nishida, and J. Siekmann, "Development of a WHO growth reference for school-aged children and adolescents," Bulletin of the World Health Organization, vol. 85, no. 9, pp. 660-667, 2007.

[8] S. E. Barlow and W. H. Dietz, "Obesity evaluation and treatment: expert Committee recommendations. The Maternal and Child Health Bureau, Health Resources and Services Administration and the Department of Health and Human Services," Pediatrics, vol. 102, no. 3, article E29, 1998.

[9] J. S. Duncan, E. K. Duncan, and G. Schofield, "Accuracy of body mass index (BMI) thresholds for predicting excess body fat in girls from five ethnicities," Asia Pacific Journal of Clinical Nutrition, vol. 18, no. 3, pp. 404-411, 2009.

[10] A. Must, G. E. Dallal, and W. H. Dietz, "Reference data for obesity: 85 th and 95th percentiles of body mass index (wt/ht ${ }^{2}$ ) and triceps skinfold thickness," American Journal of Clinical Nutrition, vol. 53, no. 4, pp. 839-846, 1991.

[11] A. Must, G. E. Dallal, and W. H. Dietz, "Reference data for obesity: 85 th and 95 th percentiles of body mass index $\left(\mathrm{wt} / \mathrm{ht}^{2}\right)$ a correction," American Journal of Clinical Nutrition, vol. 54, no. 5, article 773, 1991.

[12] "Health Behaviour of School-aged Children study," http://www .hbsc.org/.

[13] C. L. Ogden, M. D. Carroll, B. K. Kit, and K. M. Flegal, "Prevalence of obesity and trends in body mass index among US children and adolescents, 1999-2010," Journal of the American Medical Association, vol. 307, no. 5, pp. 483-490, 2012.

[14] "Commonwealth Scientific Industrial Research Organisation (CSIRO), University of South Australia: user Guide: 2007 Australian National Children's Nutrition and Physical Activity Survey," http://www.health.gov.au/internet/main/publishing .nsf/Content/phd-nutrition-childrens-survey-userguide.

[15] S. P. Reddy, S. James, R. Sewpaul et al., "Umthente Uhlaba Usamila-The South African Youth Risk Behaviour. South African Medical Research Council," 2010, http://www.mrc.ac .za/healthpromotion/yrbs_2008_final_report.pdf.

[16] P. Bovet, A. Chiolero, G. Madeleine, A. Gabriel, and N. Stettler, "Marked increase in the prevalence of obesity in children of the Seychelles, a rapidly developing country, between 1998 and 2004," International Journal of Pediatric Obesity, vol. 1, no. 2, pp. 120-128, 2006.
[17] H. Aounallah-Skhiri, H. B. Romdhane, P. Traissac et al., "Nutritional status of Tunisian adolescents: associated gender, environmental and socio-economic factors," Public Health Nutrition, vol. 11, no. 12, pp. 1306-1317, 2008.

[18] M. Shields and M. S. Tremblay, "Canadian childhood obesity estimates based on WHO, IOTF and CDC cut-points," International Journal of Pediatric Obesity, vol. 5, no. 3, pp. 265-273, 2010.

[19] A. Bonvecchio, M. Safdie, E. A. Monterrubio, T. Gust, S. Villalpando, and J. A. Rivera, "Overweight and obesity trends in Mexican children 2 to 18 years of age from 1988 to 2006," Salud Pública de México, vol. 51, supplement 4, pp. S586-S594, 2009.

[20] G. K. Singh, M. D. Kogan, and P. C. Van Dyck, "Changes in state-specific childhood obesity and overweight prevalence in the United States from 2003 to 2007," Archives of Pediatrics and Adolescent Medicine, vol. 164, no. 7, pp. 598-607, 2010.

[21] A. M. Al-Sendi, P. Shetty, and A. O. Musaiger, "Prevalence of overweight and obesity among Bahraini adolescents: a comparison between three different sets of criteria," European Journal of Clinical Nutrition, vol. 57, no. 3, pp. 471-474, 2003.

[22] Y. Li, E. G. Schouten, X. Hu, Z. Cui, D. Luan, and G. Ma, "Obesity prevalence and time trend among youngsters in China, 1982-2002," Asia Pacific Journal of Clinical Nutrition, vol. 17, no. 1, pp. 131-137, 2008.

[23] R. Kelishadi, G. Ardalan, R. Gheiratmand et al., "Thinness, overweight and obesity in a national sample of Iranian children and adolescents: CASPIAN Study," Child, vol. 34, no. 1, pp. 44$54,2008$.

[24] D. Nitzan Kaluski, G. Demem Mazengia, T. Shimony, R. Goldsmith, and E. M. Berry, "Prevalence and determinants of physical activity and lifestyle in relation to obesity among schoolchildren in Israel," Public Health Nutrition, vol. 12, no. 6, pp. 774-782, 2009.

[25] Y. S. Khader, A. Batieha, H. Jaddou, Z. Batieha, M. El-Khateeb, and K. Ajlouni, "Metabolic abnormalities associated with obesity in children and adolescents in Jordan," International Journal of Pediatric Obesity, vol. 6, no. 3-4, pp. 215-222, 2011.

[26] A. Bener, "Prevalence of obesity, overweight, and underweight in Qatari adolescents," Food and Nutrition Bulletin, vol. 27, no. 1, pp. 39-45, 2006.

[27] M. I. El Mouzan, P. J. Foster, A. S. Al Herbish et al., "Prevalence of overweight and obesity in Saudi children and adolescents," Annals of Saudi Medicine, vol. 30, no. 6, pp. 203-208, 2010, Erratum in: Annals of Saudi Medicine, vol. 30, 500-502, 2010.

[28] T.-H. Liou, Y.-C. Huang, and P. Chou, "Prevalence and secular trends in overweight and obese Taiwanese children and adolescents in 1991-2003," Annals of Human Biology, vol. 36, no. 2, pp. 176-185, 2009.

[29] S. W. Ng, S. Zaghloul, H. Ali et al., "Nutrition transition in the United Arab Emirates," European Journal of Clinical Nutrition, vol. 65, no. 12, pp. 1328-1337, 2011.

[30] S. C. Savva, Y. Kourides, M. Tornaritis, M. Epiphaniou-Savva, C. Chadjigeorgiou, and A. Kafatos, "Obesity in children and adolescents in Cyprus. Prevalence and predisposing factors," International Journal of Obesity, vol. 26, no. 8, pp. 1036-1045, 2002.

[31] M. Kunesova, J. Vignerova, A. Steflová et al., "Obesity of Czech children and adolescents: relation to parental obesity and socioeconomic factors," Journal of Public Health, vol. 15, no. 3, pp. 163-170, 2007.

[32] S. Blüher, C. Meigen, R. Gausche et al., "Age-specific stabilization in obesity prevalence in German children: a cross-sectional 
study from 1999 to 2008," International Journal of Pediatric Obesity, vol. 6, no. 2, pp. e199-e206, 2011.

[33] T. Tzotzas, E. Kapantais, K. Tziomalos et al., "Epidemiological survey for the prevalence of overweight and abdominal obesity in Greek adolescents," Obesity, vol. 16, no. 7, pp. 1718-1722, 2008.

[34] A. Vieno, M. Santinello, and M. C. Martini, "Epidemiology of overweight and obesity among Italian early adolescents: relation with physical activity and sedentary behaviour," Epidemiologia e Psichiatria Sociale, vol. 14, no. 2, pp. 100-107, 2005.

[35] H. Whelton, J. Harrington, E. Crowley, V. Kelleher, M. Cronin, and I. J. Perry, "Prevalence of overweight and obesity on the island of Ireland: results from the North South Survey of Children's Height, Weight and Body Mass Index, 2002," BMC Public Health, vol. 7, article 187, 2007.

[36] L. B. Sardinha, R. Santos, S. Vale et al., "Prevalence of overweight and obesity among Portuguese youth: a study in a representative sample of 1018-year-old children and adolescents," International Journal of Pediatric Obesity, vol. 6, no. 2, pp. e124-e128, 2011.

[37] Ö. B. Ekblom, K. Oddsson, and B. T. Ekblom, "Prevalence and regional differences in overweight in 2001 and trends in BMI distribution in Swedish children from 1987 to 2001," Scandinavian Journal of Public Health, vol. 32, no. 4, pp. 257263, 2004.

[38] M. L. Booth, T. Dobbins, A. D. Okely, E. Denney-Wilson, and L. L. Hardy, "Trends in the prevalence of overweight and obesity among young Australians, 1985, 1997, and 2004," Obesity, vol. 15, no. 5, pp. 1089-1095, 2007.

[39] J. Utter, S. Denny, S. Crengle et al., "Overweight among New Zealand adolescents: associations with ethnicity and deprivation," International Journal of Pediatric Obesity, vol. 5, no. 6, pp. 461-466, 2010.

[40] R. M. Tassitano, M. V. G. D. Barros, M. C. M. Tenório, J. Bezerra, and P. C. Hallal, "Prevalence of overweight and obesity and associated factors among public high school students in Pernambuco State, Brazil," Cadernos de Saúde Pública, vol. 25, no. 12, pp. 2639-2652, 2009.

[41] G. T. C. Ko, R. Ozaki, G. W. K. Wong et al., "The problem of obesity among adolescents in Hong Kong: a comparison using various diagnostic criteria," BMC Pediatrics, vol. 8 , article 10, 2008.

[42] R. Bishwalata, A. B. Singh, A. J. Singh, L. U. Devi, and R. K. Bikramjit Singh, "Overweight and obesity among schoolchildren in Manipur, India," National Medical Journal of India, vol. 23, no. 5, pp. 263-266, 2010.

[43] N. N. Abu Baker and S. M. Daradkeh, "Prevalence of overweight and obesity among adolescents in irbid governorate, Jordan," Eastern Mediterranean Health Journal, vol. 16, no. 6, pp. 657$662,2010$.

[44] K. Søren and C. Jo, "The prevalence of overweight and obesity among Danish school children," Obesity Reviews, vol. 11, no. 7, pp. 489-491, 2010.

[45] H. Thibault, B. Contrand, E. Saubusse, M. Baine, and S. Maurice-Tison, "Risk factors for overweight and obesity in French adolescents: physical activity, sedentary behavior and parental characteristics," Nutrition, vol. 26, no. 2, pp. 192-200, 2010.

[46] Y. Manios, P. D. Angelopoulos, G. Kourlaba et al., "Prevalence of obesity and body mass index correlates in a representative sample of Cretan school children," International Journal of Pediatric Obesity, vol. 6, no. 2, pp. 135-141, 2011.

[47] Á. Baráth, K. Boda, M. Tichy, É. Károly, and S. Túri, "International comparison of blood pressure and BMI values in schoolchildren aged 11-16 years," Acta Paediatrica, International Journal of Paediatrics, vol. 99, no. 2, pp. 251-255, 2010.

[48] F. Velluzzi, A. Lai, G. Secci et al., "Prevalence of overweight and obesity in Sardinian adolescents," Eating and Weight Disorders, vol. 12, no. 2, pp. e44-e50, 2007.

[49] R. Baratta, C. Degano, D. Leonardi, R. Vigneri, and L. Frittitta, "High prevalence of overweight and obesity in 11-15-year-old children from Sicily," Nutrition, Metabolism and Cardiovascular Diseases, vol. 16, no. 4, pp. 249-255, 2006.

[50] M. Jodkowska, A. Oblacinska, and I. Tabak, "Overweight and obesity among adolescents in Poland: gender and regional differences," Public Health Nutrition, vol. 13, no. 10, pp. 16881692, 2010.

[51] M. M. Bibiloni, E. Martinez, R. Llull, M. D. Juarez, A. Pons, and J. A. Tur, "Prevalence and risk factors for obesity in Balearic Islands adolescents," British Journal of Nutrition, vol. 103, no. 1, pp. 99-106, 2010.

[52] P. Henríquez Sánchez, J. Doreste Alonso, P. Laínez Sevillano et al., "Prevalence of obesity and overweight in adolescents from Canary Islands, Spain. Relationship with breakfast and physical activity," Medicina Clínica, vol. 130, pp. 606-610, 2008.

[53] A. M. Lasserre, A. Chiolero, F. Cachat, F. Paccaud, and P. Bovet, "Overweight in Swiss children and associations with children's and parents' characteristics," Obesity, vol. 15, no. 12, pp. 29122919, 2007.

[54] N. Öner, Ü. Vatansever, A. Sari et al., "Prevalence of underweight, overweight and obesity in Turkish adolescents," Swiss Medical Weekly, vol. 134, no. 35-36, pp. 529-533, 2004.

[55] A. C. F. De Moraes, R. P. Fadoni, L. M. Ricardi et al., "Prevalence of abdominal obesity in adolescents: a systematic review," Obesity Reviews, vol. 12, no. 2, pp. 69-77, 2011.

[56] T. Lobstein, L. Baur, and R. Uauy, "Obesity in children and young people: a crisis in public health," Obesity Reviews, vol. 5, supplement 1, pp. 4-85, 2004.

[57] S. Low, M. C. Chin, and M. Deurenberg-Yap, "Review on epidemic of obesity," Annals of the Academy of Medicine Singapore, vol. 38, no. 1, pp. 57-59, 2009.

[58] L. Serra Majem, L. Ribas Barba, J. Aranceta Bartrina, C. Pérez Rodrigo, P. Saavedra Santana, and L. Peña Quintana, "Childhood and adolescent obesity in Spain. Results of the enKid study (1998-2000)," Medicina Clinica, vol. 121, no. 19, pp. 725-732, 2003.

[59] J. Aranceta, C. Pérez Rodrigo, L. Serra Majem et al., "Prevalencia de la obesidad en España: resultados del estudio SEEDO, 2000," Medicina Clínica, vol. 120, pp. 608-612, 2003.

[60] J. Kain, R. Uauy, F. Vio, and C. Albala, “Trends in overweight and obesity prevalence in Chilean children: comparison of three definitions," European Journal of Clinical Nutrition, vol. 56, no. 3, pp. 200-204, 2002.

[61] L. Monasta, T. Lobstein, T. J. Cole, J. Vignerová, and A. Cattaneo, "Defining overweight and obesity in pre-school children: IOTF reference or WHO standard?" Obesity Reviews, vol. 12, no. 4, pp. 295-300, 2011.

[62] L. A. Moreno, M. G. Blay, G. Rodríguez et al., "Screening performances of the International Obesity Task Force body mass index cut-off values in adolescents," Journal of the American College of Nutrition, vol. 25, no. 5, pp. 403-408, 2006.

[63] M. De Onis and T. Lobstein, "Defining obesity risk status in the general childhood population: which cut-offs should we use?" International Journal of Pediatric Obesity, vol. 5, no. 6, pp. 458460, 2010. 
[64] J. J. Reilly, J. Kelly, and D. C. Wilson, "Accuracy of simple clinical and epidemiological definitions of childhood obesity: systematic review and evidence appraisal," Obesity Reviews, vol. 11, no. 9, pp. 645-655, 2010.

[65] D. S. Freedman, J. Wang, J. C. Thornton et al., "Racial/ethnic differences in body fatness among children and adolescents," Obesity, vol. 16, no. 5, pp. 1105-1111, 2008.

[66] J. J. Reilly, "Obesity in childhood and adolescence: evidence based clinical and public health perspectives," Postgraduate Medical Journal, vol. 82, no. 969, pp. 429-437, 2006. 